\title{
O LÚDICO NO DESENVOLVIMENTO DA CRIANÇA COM PARALISIA CEREBRAL ESPÁSTICA
}

\author{
PLAYING GAMES IN THE DEVELOPMENT OF CHILDREN \\ WITH SPASTIC CEREBRAL PALSY
}

Regina Cristiane N. C. Peres*

Peres RCNC. O lúdico no desenvolvimento da criança com paralisia cerebral espástica. Reli Brus Cresc Deserta Huii 004; 14(3): 37-46.

\begin{abstract}
Resumo: O presente estudo teve como objetivo construir um ambiente lúdico constituído de jogos e brincadeiras com a finalidade de estimular o desenvolvimento $\mathrm{co}^{\wedge} \mathrm{cnitivo}$ c motor de crianças com paralisia cerebral espástica em idade pré-escolar. O estudo se fundamenta na teoria sócio-histórica de $\mathrm{Vy}^{\wedge} \mathrm{cotsky} \sim$ que considera que as atividades lúdicas interferem no processo de desenvolvimento motor e coercitivo da criança em idade pré-escolar, uma vez que por intermédio das brincadeiras a criança pode exercitar suas potencialidades. Sete crianças em idade pré-escolar com paralisia cerebral espástica participaram de um programa de intervenção com jogos e brincadeiras durante o período de um semestre. totalizando vinte e seis sessões. Os resultados indicaram que j ogos e brincadeiras podem facilitar o desenvolvimento cognitivo e motor destas crianças, pois houve melhora quanto à coordenação, ao equilíbrio e à preensão dos objetos. Foi também observada melhora na atenção das crianças, com discriminação e aprendizado de cores.
\end{abstract}

Palavras-chaves: Educação. Educação especial. Paralisia cerebral. Atividades lúdicas. Desenvolvimento.

\section{INTRODUÇÃO}

Sabemos que os jogos e brincadeiras permeiam o universo da criança e que fazem parte da existência humana' - 7. A criança se desenvolve por meio do jogo, desempenha papéis que não são possíveis para sua idade, exercita a imaginação, a memória e a concentração, explora objetos e constrói sua imagem corporal, enfim, aprende como funciona o mundo, podendo agir nele e construindo o seu conhecimento. Podemos afirmar que é fascinante observar uma criança brincando e desenvolvendo-se.

Este trabalho procura mostrar que of erecendo condições adequadas e oportunidades de "brincar" para crianças com paralisia cerebral, podemos facilitar seu desenvolvimento cognitivo e motor e, consequentemente, a sua inserção social, pois a dificuldade motora apresentada por estas crianças pode interferir na interação destas com o meio em que vivem e esconder aos olhos da sociedade suas reais potencialidades.

Nesse sentido, escolhemos como embasamento teórico para o processo de desenvolvimento a teoria sócio-histórica por acreditarmos que os processos psicológicos superiores têm origem sócio-cultural. Somos favoráveis à idéia de que é o desenvolvimento sócio-histórico e cultural que nos constitui como seres humanos. Assim, discutiremos o processo de desenvolvi-

* Doutora em Educação - área de concentração: Educação Especial - USP; mestre em Educação Especial UFSCar. Endereço: Rua Wady Butara, 978 -Maresia- SP CEP: 17.514-730 Telefones: (14) 423.3937 ou 9717.5639 - E-mail: crisnperes@flash.tv.br 
mento do deficiente na perspectiva de Vygotsky, que foi um dos maiores representantes da teoria sócio-histórica, estudando exaustivamente o papel social no processo humano de desenvolvimento e aprendizagem.

\section{Deficiência e desenvolvimento na perspectiva de Vygotsky}

Para Vygotsky ${ }^{8}$, o desenvolvimento de uma criança deficiente não é inferior ao desenvolvimento de outras crianças, e sim, diferente, singular. A criança com paralisia cerebral espástica, que apresenta dificuldade para se movimentar e por isso não tem as mesmas chances de desenvolvimento de esquema corporal, percepção espacial, de tempo, dominância corporal, entre outros, vai elaborar qualitativa e diferentemente suas funções psicológicas superiores, apresentando um desenvolvimento psíquico particular. Ela aprende caminhos novos para compensar essa deficiência (supercompensação), pois lhe falta a experiência motora para a elaboração de seu pensamento.

Desse modo, os organismos das crianças deficientes entram "obrigatoriamente em luta, em conflito com o meio exterior ao qual eles devem se adaptar" (Adler, 1972 apud $^{8}$, p. 87), contribuindo positivamente para seu desenvolvimento.

Vygotsky vê a experiência social como alicerce de processos compensatórios que podem harmonizar os processos de carência e servir à elaboração de funções superiores.

Ó defeito, na visão de Vygotsky, é um potencial estimulador do crescimento de mecanismos compensatórios do desenvolvimento, funcionando como instigador de novos caminhos para o desenvolvimento das funções superiores, É essa a transformação "do menos (defeito) para o mais" (compensação) $^{8}$ (p. 21).

As exigências sociais podem estimular o desenvolvimento da criança, pois quanto mais estimulada socialmente, mais vias compensatórias ela terá que criar para satisfazer suas necessidades. Todo ser humano é bombardeado diariamente com estímulos para reagir ao meio social. Basta investigar os meios necessários para estimular o desenvolvimento e observar a reação singular de cada ser humano.

Já que o defeito provoca um desvio e cria uma nova forma de desenvolvimento e a sociedade está preparada somente para o desenvolvimento típico, ou seja, o que ocorre com maior freqüência, uma pessoa para a qual o desenvolvimento transcorra de maneira diferente (atípico) não pode se integrar de maneira natural à sociedade ${ }^{8}$.
A falha se inicia em relação à conceituação, qual seja, definir uma criança pela deficiência, ou seja, uma criança com retardo mental ou com deficiência física, não auxilia vê-la com sua individualidade positiva. O olhar se centra no "defeito" e nada se aprende sobre o seu potencial de desenvolvimento.

Além disso, que maravilhoso universo se mostra quando a sociedade "aprende que o defeito não é apenas uma inferioridade, uma falta, uma fraqueza, mas um algo a mais, uma fonte de força e de aptidão, que nele existe uma conotação positiva!”8 (p.93).

As formas coletivas de colaboração são os alicerces, as "fontes de construção das formas individuais de comportamento"” (p. 167). Dessa forma, é a partir da interação entre os homens, da qual surgem conflitos, da experiência social e da colaboração das crianças com seu meio, que se desenvolvem as funções superiores de pensamento.

Neste artigo, ressalta-se a importância das atividades lúdicas que servem como recurso para promover a interação entre as crianças e, conseqüentemente, o seu desenvolvimento cognitivo e motor.

\section{Atividades lúdicas Conto recurso no processo de desenvolvimento}

Friedmann ${ }^{9}$ aponta que "as interações sociais que a criança estabelece no decorrer da atividade lúdica são fundamentais para o seu desenvolvimento. Durante essas trocas, a criança tem oportunidade de assumir diversos papéis e colocar-se no lugar do outro" (p. 27). Assim, os temas dos jogos são originados pelo contexto social e pela exigência da vida da criança inserida na sociedade.

Existe, nas crianças e nos animais, um "instinto" que os impulsiona ao ato de brincar, pela necessidade de se desenvolverem fisicamente; a isto, mais especificamente nos seres humanos, acrescentaríamos o valor do relacionamento humano, a necessidade de se agrupar e, portanto, de se desenvolver enquanto um ser social.

Para Elkonin ${ }^{6}$, o jogo se configura na forma de educação infantil, e se dá espontaneamente e de maneira eficaz, pois a criança "ao manipular seus brinquedos, procura projetar-se no mundo, abrir-se para conquistas e aquisições, no intuito de melhor se situar em relação aquilo que Ihe é exterior "6 (p. 17).

Desse modo, a criança experimenta e relaciona seu mundo interno com a realidade externa, participando desse mundo e percebendo seu papel nele".

A brincadeira e o jogo têm um aspecto sedutor quando utilizados pelo educador para a 
aprendizagem. No entanto, somente o educador tem consciência dessa função, pois, "trata-se de utilizar o interesse da criança pela brincadeira a fim de desviá-la, de utilizá-la para uma boa causa"17 (p. 97).

Desse modo, para o professor, o jogo tem um caráter de recurso de ensino, enquanto para a criança é uma atividade do seu dia-adia. O trabalho do professor, nesse contexto, deve ser o de organizador da sala de aula como espaço lúdico, selecionando jogos que facilitem o desenvolvimento cognitivo, sócio-afetivo e motor do aluno.

Assim, a criança terá a oportunidade de escolher os jogos para brincar, posto que, uma vez que a escolha do jogo seja arbitrária, o jogo perde o seu caráter lúdico e passa a ser apenas material pedagógico. O professor deve ouvir a criança e, a partir das suas dúvidas, deixá-la trabalhar de maneira espontânea na construção do conhecimento".

Utilizando o jogo e o brinquedo, a criança tem a oportunidade de satisfazer uma série de necessidades, como de dominância e cooperação, que podem ser utilizadas como recurso para a aprendizagem. Ainda, nos jogos e brincadeiras, emergem valores que dizem respeito à curiosidade e à coragem, levando à autoaceitação, ao otimismo, à alegria e aos contatos sociais; com eles, a criança amplia seu campo de atuação, vivenciando atitudes diferentes e avaliando suas possibilidades como participante de um grupo. "Isso mostra que o jogo e a brincadeira são recursos educacionais que podem facilitar o desenvolvimento de novas habilidades motoras e acadêmicas, sem que sejam impostos à criança.

Lorenzini $^{7}$ mostrou que um ambiente de brincadeiras entre mães e filhos com paralisia cerebral contribuiu positivamente para o desenvolvimento sensório-motor da criança. A autora ainda destaca que:

a brincadeira constitui, para a criança, um desafio. Ao mesmo tempo, possibilita-lhe atingir a meta desejada com o seu próprio esforço, favorecendo a troca com o meio e, com isso, o seu desenvolvimento motor, sensorial, cognitivo, afetivo e social (p. 120).

Ainda sobre a aprendizagem de habilidades motoras, Le Boulch ${ }^{15}$ eMeureStaes $^{16}$ sugerem jogos para facilitar o desenvolvimento global em crianças normais por acreditarem que a função motora, o desenvolvimento intelectual e afetivo estão intimamente relacionados na criança, posto que o jogo a envolve, estimula o desenvolvimento de sua afetividade e é altamente gratificante.

"A criança é uma unidade, um ser total. Qualquer coisa que ela faça é realizada pela tota- lidade do seu ser. Quando brinca envolve seu corpo todo e sua mente"1 (p. 87).

Assim, se o professor estimular uma área de desenvolvimento, estará influenciando o desenvolvimento de outra; por exemplo, estimulando o desenvolvimento motor, o professor estará facilitando o desenvolvimento cognitivo.

Sobre isso, Finnie ${ }^{17}$ descreve que uma criança normal, desde o nascimento, manipula o próprio corpo, o berço e os objetos e, dessa maneira, aprende a diferença de textura, peso, tamanho, cores, como manipular objetos, aprende qual a força que deve ser aplicada para levantar um objeto ou para colocá-lo em outro lugar. Ela, por meio da manipulação, explorando objetos, pode aprender onde eles estão: de um lado, de outro, em cima, em baixo, dentro, fora. Aprende, ainda, a calcular a distância, a largura, o que fazer para provocar um som e como utilizar um brinquedo. Pode, ao brincar, passar por cima ou por baixo de objetos, por espaços estreitos e, com isso, adquirir conceitos importantes para o seu desenvolvimento: lateralidade, profundidade, distância e esquema corporal. Assim, aprende e compreende como funciona o mundo, podendo agir nele e construir seu conhecimento.

No caso da criança com paralisia cerebral, com dificuldade de se movimentar, explorar seu corpo ou explorar o meio em que vive, pode ser difícil o desenvolvimento da percepção corporal e o entendimento de sua ação no mundo, dado que os conceitos necessários para essa compreensão estão intrinsecamente ligados à experiência motora.

Finnie $^{17}$ (p. 265) afirma que "a deficiência a impede de aprender através do brinquedo de um modo natural de modo que, a menos que ela tenha ajuda e encorajamento, ela não será capaz de aprender quando brinca ou de alcançar seu potencial”. O papel do professor em sala de aula é promover essa ajuda e encorajamento.

Como aponta Carvalho ${ }^{5}$ (p. 145) em um estudo realizado com sete famílias, nas quais um de seus elementos sofre de paralisia cerebral:

"As brincadeiras das crianças com PC são limitadas em decorrência de vários fatores, tais como: acesso aos espaços físicos, falta de companheiros para brincar, pouco contato com outras crianças e restrita variação dos tipos de brincadeiras".

Assim entendidas, as atividades lúdicas, essenciais para o desenvolvimento da criança com paralisia cerebral, podem romper os fatores lirnitantes que as impedem de brincar. A presente pesquisa teve como objetivo proporcionar a sete crianças em idade pré-escolar com paralisia cerebral espástica, matriculadas em uma sala de aula 
para crianças especiais, uma experiência de vivenciar as manifestações lúdicas, com base na teoria sócio-histórica de Vygotsky, adequando o seu ambiente escolar, estimulando o seu desenvolvimento cognitivo e motor, assim como a interação entre elas.

\section{MATERIAL E MÉTODO}

A metodologia qualitativa, modalidade estudo de caso, foi considerada a mais adequada para realizar este estudo. A utilização da pesquisa qualitativa nas áreas das Ciências Humanas, em especial em Educação e Ciências Sociais, representou uma alternativa de investigação que buscava fugir da rigidez das pesquisas positivistas que utilizavam os mesmos métodos das ciências físicas e naturais para os estudos dos fenômenos sociais e educacionais ${ }^{18}$. O que se busca neste tipo de investigação é a compreensão do fenômeno único, sem a característica da generalização.

Para a seleção das crianças, foram consultados os prontuários de uma escola para crianças com necessidades educativas especiais na cidade de Cascavel, região oeste do Paraná, e selecionadas sete crianças de duas salas de aula, segundo o critério idade (entre três a seis anos) e diagnóstico clínico (crianças com paralisia cerebral espástica). Destas sete crianças, três eram meninos e quatro meninas, com idades de três anos e três meses a seis anos.

Os instrumentos de avaliação e/ou coleta foram compostos por: um formulário de caracterização da escola das crianças, um roteiro de entrevista pré-intervenção e outro pós-intervenção para as mães e professoras das crianças, com questões fechadas e abertas sobre dados sócio-demográficos e sobre o conhecimento e expectativas de mães e professoras quanto ao desenvolvimento motor e cognitivo das crianças, formulário para investigação da área de cognição e de desenvolvimento motor do Inventário Portage ${ }^{19}$ e diário de campo no qual eram descritas as sessões de intervenção e os aspectos relevantes quanto ao desenvolvimento motor e cognitivo das crianças.

Os materiais utilizados durante a intervenção foram: folha de papel sulfite, lápis de cor, relógio, bolas de diferentes cores, blocos, objetos coloridos de diferentes formas, tamanhos, cores e pesos, tintas, pincéis, massa de modelar, bonecas, carrinhos, telefone, dominó de cores, jogo de boliche confeccionado com latas pintadas em cores diferentes, caixa com objetos de tamanhos, formatos e texturas diferentes, tampinhas e botões coloridos, água, copo, areia, folhas, pedrinhas, colchonete, almofadas, mesa e cadeira.

\section{RESULTADO E DISCUSSÃO}

\section{Avaliação das crianças pré-intervenção}

Considerando o pressuposto teórico sóciohistórico de Vygotsky, o desenvolvimento da inteligência é produto da convivência social e das condições biológicas de cada ser humano que podem diferir qualitativamente. No entanto, a elaboração das informações recebidas pelo meio que estimulam o desenvolvimento da criança necessita ser intermediada pelas pessoas que com ela convivem.

Como cada criança é um ser único e o processo de aprendizagem deve partir dos estímulos do meio que são motivadores para ela, foi investigado o meio em que ela vivia quanto aos dados sobre o conhecimento e as expectativas que suas mães e professoras tinham em relação ao seu desenvolvimento motor e cognitivo. Além disso, realizou-se uma avaliação em relação aos aspectos cognitivos e motores destas crianças, utilizando o Inventário Portagem.

\section{Entrevista com as mães das crianças}

Os dados obtidos nas entrevistas mostraram que, em relação às atividades de vida diária, como: vestir-se, alimentar-se, escovar os dentes, pentear-se, alimentar-se e ir ao banheiro, duas crianças realizavam sozinhas tais atividades, três realizavam com ajuda e duas não o faziam, sendo dependentes de suas mães para tais atividades.

Quanto ao lazer, cinco crianças brincavam na maior parte do tempo com os irmãos (duas ou três vezes na semana), porém raramente com amigos. Duas quase não brincavam. Segundo as mães, elas não gostavam de brincar pela dificuldade de preensão dos objetos, o que as fazia perderem o interesse pela atirvidade.

Apenas duas mães relataram que bnncavam com seus filhos; as demais "não têm tempo para brincar", embora relatassem que gostariam de poder dar mais atenção aos filhos. Os brinquedos ou brincadeiras que apareceram com maior frequência como prediletos foram bola, jogos de montar, carrinho, quebra-cabeças, atividades de pintar e desenhar, brincar na água e na terra.

Estas informações foram relevantes na escolha dos brinquedos a serem utilizados na intervenção.

Quando indagadas sobre o desenvolvimento de seus filhos, todas se mostraram muito preocupadas com o desenvolvimento motor e com o desempenho de seus filhos na escola.

Todas as mães disseram que gostariam que seus filhos melhorassem o equilíbrio e a coordenação, pois eles tropeçavam muito e tinham dificuldades para se vestir e comer; dois alunos 
$(28,5 \%)$ não conseguiam realizar tais tarefas. Quatro mães (57\%) disseram que gostariam que seus filhos melhorassem a marcha.

Em relação ao desenvolvimento cognitivo, cinco mães (71,5\%) gostariam que os filhos aprendessem os números e as cores pois achavam que eles estavam muito atrasados. Duas mães (28,5\%) referiram-se somente ao aprendizado das cores. Uma mãe (14\%) disse que gostaria que a filha melhorasse a atenção.

\section{Entrevista com as professoras das crianças}

Pelos relatos obtidos na entrevista com as duas professoras, verificou-se que ambas cursavam o último ano de pedagogia, uma delas trabalhava com educação especial há seis anos e a outra há 15 anos.

Sobre a prática pedagógica utilizada em sala de aula, ambas utilizavam a teoria construtivista, sendo esta a proposta pedagógica da escola.

Em relação ao uso de atividades lúdicas em sala de aula, ambas ressaltaram a importancia da utilização de jogos e brincadeiras como fator de desenvolvimento do raciocínio, da memória, da criatividade e do respeito a normas e regras. No entanto, utilizavam as atividades lúdicas “em atividades livres [...] nas horas de folga”, não as utilizando efetivamente como recurso facilitador da aprendizagem. A este respeito, para BlascoviAssis ${ }^{2}{ }^{\wedge} 0$ (p. 116) “o lazer [...] acaba sendo visto apenas como um meio de passar o tempo, sendo desprovido de um caráter educacional”.

A informação mais relevante fornecida por estas duas docentes diz respeito aos seus objetivos de ensino em relação ao desenvolvimento cognitivo e motor de seus alunos que devem ser comparadas com as expectativas das mães em relação ao desenvolvimento de seus filhos.

Segundo as professoras, $100 \%$ (sete crianças) necessitam melhorar a coordenação motora, $28,5 \%$ (duas crianças) o equilíbrio e outros $28,55 \%$ (duas crianças) a marcha.

Quanto à cognição,86\% (seis crianças) deveriam ser estimuladas a aprender cores, 57\% (quatro crianças) formas geométricas, 57\% (quatro crianças) texturas, 28,5\% (duas crianças) números e quantidades, $28,5 \%$ (duas crianças) tamanhos e 14\% (uma criança) melhorar a atenção, concentração e memória.

\section{Avaliação das crianças segundo o inventário portage}

A avaliação das crianças pelo Inventário Portage permitiu observar que, em relação ao desenvolvimento cognitivo, os maiores escores fo- ram encontrados nos intervalos referentes aos desempenhos 65 ao 86" (item 9, p. 197-202). As sete crianças (100\%) não apresentaram: apanhar um determinado número de objetos ao ser requisitado (de um a cinco), nomear cinco texturas diferentes, copiar um triângulo ao ser requisitado, dizer o momento do dia associado a cada atividade, repetir rimas familiares, nomear oito cores, identificar o valor de três moedas e emparelhar símbolos, letras e números (desempenhos 65, 66, 67, 69, 70, 73, 74 e 75).

Quanto aos dados referentes ao desenvolvimento motor das crianças, os maiores escores foram encontrados nos intervalos referentes aos desempenhos de 95 ao $109^{19}$ (item 12, p. 255256). Cinco crianças $(71,5 \%)$ não apresentaram os desempenhos 96 (ficar em um só pé sem apoio), 99 (pular para frente 10 vezes sem cair), 101 (pular de costas seis vezes) e 104 (recortar em torno de linhas curvas); e quatro crianças (57\%) não apresentaram os desempenhos 86 (corre dez passos, coordenando e alternando o movimento dos braços e pés), 97 (muda de direção ao correr), 100 (salta sobre uma corda suspensa a $5 \mathrm{~cm}$ do solo), 102 (rebate e apanha uma bola grande), 103 (um, dois a três pedaços de massa de modelar), 105 (encaixa objetos de rosca), 106 (desce escadas alternando os pés), 107 (pedala um triciclo, fazendo curvas) e 109 (recorta um círculo de $5 \mathrm{~cm}$ ). Seis crianças (85,5\%) não apresentaram os desempenhos 98 (anda sobre uma viga ou tábua mantendo o equilíbrio) e 108 (salta em um só pé, cinco vezes consecutivas).

\section{Avaliação global das criancas e seleção dos desempenhos a serem estimulados durante a intervenção}

Após a análise dos dados obtidos na avaliação das crianças por meio do Inventário Portage e das entrevistas realizadas com as mães e com as professoras das crianças, foram identificados alguns desempenhos que as crianças não conseguiam executar e para os quais necessitavam de estimulação.

Foram considerados, como prioridade para a intervenção, os desempenhos avaliados pelas mães das crianças, por sua importância no meio social em que a criança vive.

Em seguida, foram analisados os desempenhos levantados pelas entrevistas realizadas com as professoras e, a partir do cruzamento destes dados, foram considerados os dados obtidos pela avaliação do Inventário Portage.

Desta rede de informações, foram selecionados os desempenhos a serem estimulados durante a intervenção (Quadro I ). 
Quadro 1. Desempenhos a serem estimulados durante a intervenção

\begin{tabular}{ll}
\hline \multicolumn{1}{c}{ DESEMPENHOS A SEREM ESTIMULADOS } & \multicolumn{1}{c}{ DESEMPENHOS A SEREM ESTIMULADOS } \\
\multicolumn{1}{c}{ QUANT COGNIÇÃO } & QUANTO AO DESENVOLVIMENTO MOTOR \\
\hline - Aprender números e quantidade & - Equilíbrio \\
- Aprender as cores & - Coordenação \\
- Aprender formas geométricas & - Marcha \\
- Aprender texturas & \\
- Aprender noções de tamanho & \\
- Melhorar atenção & \\
- Melhorar concentração & \\
- Melhorar memória
\end{tabular}

Quanto ao desenvolvimento motor, consideramos três classes gerais de desempenhos que aparecem no relato das mães e das professoras como prioritários para estimulação: melhorar o equilíbrio, a coordenação e a marcha das crianças. Estes desempenhos são considerados pré-requisitos para a realização dos desempenhos motores apontados na avaliação com o Inventário Portage.

Quanto à cognição, os desempenhos: aprender números e quantidade; aprender as cores; as formas geométricas; as texturas; noções de tamanho; e melhorar a atenção, concentração e memória, foram considerados prioritários para a intervenção por responderem às expectativas das mães e professoras, e englobarem os desempenhos obtidos durante a avaliação com o Inventário Portage.

Os desempenhos apresentados no Quadro 1 constituíram os objetivos de ensino a serem estimulados durante o processo de intervenção.

\section{Intervenção}

A duração da intervenção foi de um semestre letivo, com duas sessões semanais de aproximadamente 60 minutos, totalizando 26 sessões, número este considerado adequado por Lorenzini ${ }^{7}$ (p. 54) que estipula, em seu estudo, 24 sessões para construir "uma dinâmica do brincar".

Ao chegar ao local, a pesquisadora convidava os alunos para brincar. Algumas vezes a intervenção era realizada no jardim da escola e, em outras, quando a professora estava realizando alguma atividade fora da classe, a intervenção era executada na própria classe.

Durante todas as sessões, a pesquisadora perguntava às crianças do que gostariam de brincar e espalhava diversos objetos e brinquedos em um colchonete estendido no chão. Os alunos escolhiam os brinquedos de sua preferência e a pesquisadora permitia que explorassem livremente os objetos, observando com quem eles preferiam brincar. À medida que as brincadeiras se desenvolviam, a pesquisadora se envolvia na ativida- de, buscando estimular aquelas que contribuíssem para o desenvolvimento cognitivo e motor. Participava e avaliava o desempenho de cada criança. A seguir, segue-se a descrição de uma sessão na qual podemos observar a interação entre as crianças durante a atividade lúdica de "brincar com bola” e a intervenção da pesquisadora, contribuíndo para a aprendizagem de cores e para o desenvolvimento motor.

Os nomes dos sujeitos são fictícios para preservar a identidade das crianças.

\section{SESSÃO 6 \\ ATIVIDADE: brincar com bola}

\section{OBJETIVO DAATIVIDADE:}

melhorar controle de tronco, a rotação de tronco, o equilíbrio, a coordenação, a preensão, discriminar cores amarela e vermelho

\section{DESCRIÇÃO DAATIVIDADE:}

"Hoje perguntei se gostariam de brincar no jardim e todos concordaram. Riam e conversavam muito ao sair da sala de aula.

A escola oferece um campo com muitas árvores e gramado. Sentamos embaixo das árvores, formando um círculo. Levei algumas almofadas e duas "almofadas confeccionadas com calças jeans” para posicionar as crianças. Estas almofadas pemmitem que a criança permaneça sentada com apoio de tronco. Coloquei Joana e Léo posicionados nas “calças jeans”, para conseguir um bom controle de tronco, e uma pequena almofada entre as pernas de cada um, promovendo a abdução de MMII. As outras crianças conseguiam se manter sentadas com um bom controle de tronco. Apenas coloquei uma almofada entre suas pernas para promover a abdução de MMII. As crianças sentavam-se uma ao lado da outra, formando um círculo. 
Levei vários brinquedos, mas quando Marco viu as bolas, perguntou: "Vamos bnncar de bola, tia?” Perguntei às crianças: “Quem quer brincar de bola?” e eles responderam: “Eu... eu... eu".

Havia duas bolas coloridas (uma bola vermelha e uma bola amarela). Primeiro utilizei a bola vermelha e expliquei as regras do jogo para as crianças: a bola deveria ser passada para o amiguinho que estivesse sentado ao lado e juntos iríamos cantar "Batata quente".

"Batata quente, quente, quente..."

Nesta atividade, a criança deveria segurar a bola, rodar o tronco e entregar para o amigo. Quem estivesse com a bola no final da música faria algo que os outros amigos pedissem e todos responderiam à pergunta: Qual a cor da bola?

Depois fizemos novamente o jogo com a bola amarela. Todos riam muito e pediam para os amiguinhos imitar animais quando ficavam com a bola, como: macaco, galinha. cachorro e sapo.

Nas três primeiras rodadas as crianças erraram a cor da bola, mas Léo e Marco sempre acertavam e elas se corrigiam. Após a terceira rodada, todos acertaram a cor da bola.

No decorrer da brincadeira, fiquei ao lado de Joana e Léo pela dificuldade que tinham em segurar a bola e rodar o tronco. Quando tentavam segurar a bola, inclinavam o tronco e caíam para frente ou para o lado. Fiquei atrás dos dois; quando era a vez de Joana pegar a bola, eu apoiava os seus ombros e falava: “Pega a bola, pega Joana” Ela sorria e tentava pegar a bola lentamente. Às vezes, ocorria algum movimento involuntário (pelo entusiasmo da criança e tentativa de execução do movimento muito rapidamente). Nesses momentos, eu falava: "Calma, devagar, devagar...” Joana não conseguia pegar a bola sozinha, mas com melhor posicionamento e a minha ajuda participou ativamente da brincadeira, soltava gritinhos e sorria muito.

Realizei o mesmo procedimento com Léo e, depois de algumas tentativas, ele conseguiu pegar a bola. Quando não conseguia, eu pegava a bola e colocava entre as suas mãos e o ajudava, apoiando seus cotovelos ao passar a bola para o amigo ao lado.

Marco apresenta uma boa preensão, mas quando pega a bola perde o equilíbrio. No entanto, recupera o equilíbrio rapidamente e, ao tentar jogar a bola, bastava eu dar uma orientação verbal: “Devagar, Marco, calma, isso, passa a bola, muito bem” que ele conseguia.

Ellen conseguia realizar a tarefa adequadamente, apenas apresentava um pouco de falta de coordenação para passar a bola para o amigo. Ela ficava distraída em grande parte do tempo, não pegando a bola quando o amigo Ihe passava. Várias vezes eu disse: "Pega a bola, Ellen, pega....” Dessa maneira ela pegava a bola. Notei que Ellen permanece muito distraída em todas as sessões.

Bia e Ana apresentaram muita dificuldade para jogar a bola. Quando a bola estava com elas, eu me levantava e apoiava seus ombros, evitando que caíssem para trás. Deste modo, conseguiam passar a bola e eu as elogiava: "Muito bem...Que legal..."

Rogério, ao pegar e ao jogar a bola, perdia o equilíbrio. Coloquei então duas aimofadas a seu lado, evitando que perdesse o equilíbrio de tronco. Ele conseguia realizar a atividade, com alguma falta de coordenação ao jogar a bola”.

Após cada encontro, a pesquisadora registrava em suas anotações de campo os fatos observados nos encontros procurando, da maneira mais fidedigna possível, descrever os sujeitos, reconstruir os diálogos, descrever o local no qual foi realizada a intervenção, descrever as atividades realizadas e o próprio comportamento da pesquisadora, como apontam Bodgan e Biklen (apud ${ }^{18}$ ).

As anotações de campo possibilitaram a análise dos desempenhos de cada criança, a avaliação contínua dos recursos utilizados em cada encontro e a elaboração de novas atividades (brincadeiras), já que a estratégia metodológica permitia estudar os problemas, tomar as decisões e direcionar ações para a transformação da situação.

Deste modo, as atividades lúdicas foram construídas no decorrer da intervenção, constituindo as condições facilitadoras para estimular o desempenho dos alunos.

No processo de intervenção realizado com as sete crianças, encontramos situações extremamente ricas. Deste leque de acontecimentos, registrados nas anotações de campo, os dados foram organizados fazendo as convergências das atividades escolhidas pelas crianças.

O Quadro 2 apresenta as atividades realizadas com seus respectivos objetivos e o número de sessões nas quais as atividades foram realizadas.

Podemos observar que, em cada sessão, a ênfase era dada a alguns aspectos referentes ao desenvolvimento motor e cognitivo da criança. 
Quadro 2. Descrição das atividades lúdicas realizadas durante a intervenção.

\begin{tabular}{|c|c|c|}
\hline Atividade & $\begin{array}{c}\text { Objetivo da atividade quanto ao } \\
\text { desenvolvimento cognitivo }\end{array}$ & $\begin{array}{c}\text { Objetivo da atividade quanto ao desenvolvimento } \\
\text { motor }\end{array}$ \\
\hline - Explorar livremente os brinquedos & $\begin{array}{l}\text { - Observar as crianças quanto a aspectos } \\
\text { relacionados ao desenvolvimento } \\
\text { cognitivo (conhecimento de cores e } \\
\text { formas) }\end{array}$ & $\begin{array}{l}\text { - Observar as crianças quanto a aspectos } \\
\text { relacionados ao desenvolvimento motor } \\
\text { (equilíbrio, coordenação e marcha) }\end{array}$ \\
\hline - Brincar com blocos de encaixe de & - Discriminar cores & - Melhorar coordenação motora fina \\
\hline formas e cores variadas & - Melhorar a atenção & - Melhorar o equilibrio na posição sentado \\
\hline - Brincar com tintas & $\begin{array}{l}\text { - Discriminar cores } \\
\text { - Melhorar a atenção }\end{array}$ & - Melhorar a coordenação motora fina \\
\hline - Brincar com massa de modelar & $\begin{array}{l}\text { - Discriminar cores } \\
\text { - Melhorar a atenção }\end{array}$ & - Melhorar a coordenação motora fina \\
\hline $\begin{array}{l}\text { - Brincar com jogos de encaixe, carrinho, } \\
\text { casinha e telefone }\end{array}$ & $\begin{array}{l}\text { - Discriminar cores } \\
\text { - Melhorar atenção }\end{array}$ & - Melhorar a coordenação motora grossa e fina \\
\hline - Brincar com bolas nas cores azul, & - Discriminar cores & - Melhorar equilíbrio \\
\hline vermelha e amarela & - Melhorar a atenção & - Melhorar a coordenação motora \\
\hline $\begin{array}{l}\text { - Brincar com objetos de tamanhos e } \\
\text { texturas diferentes }\end{array}$ & $\begin{array}{l}\text { - Discriminar formas e texturas } \\
\text { - Melhorar atenção }\end{array}$ & $\begin{array}{l}\text { - Melhorar a coordenação motora } \\
\text { - Melhorar o equilíbrio na posição sentado }\end{array}$ \\
\hline $\begin{array}{l}\text { - Brincar com água, areia, folhas de } \\
\text { árvore, pedrinhas e copinhos }\end{array}$ & $\begin{array}{l}\text { - Discriminar texturas } \\
\text { - Melhorar a atenção }\end{array}$ & - Melhorar a coordenação motora grossa e fina \\
\hline - Brincar com dominó de cores & $\begin{array}{l}\text { - Discriminar cores } \\
\text { - Melhorar atenção }\end{array}$ & $\begin{array}{l}\text { - Melhorar a coordenação motora fina } \\
\text { - Melhorar o equilíbrio na posição sentado }\end{array}$ \\
\hline $\begin{array}{l}\text { - Brincar de agrupar objetos de cores ou } \\
\text { formas semelhantes: tampinhas coloridas, } \\
\text { lápis de cor e botões }\end{array}$ & $\begin{array}{l}\text { - Discriminar cores } \\
\text { - Melhorar atenção }\end{array}$ & - Melhorar coordenação motora fina \\
\hline $\begin{array}{l}\text { - Brincar de boliche com latas vazias } \\
\text { pintadas de azul, amarelo e vermelho }\end{array}$ & $\begin{array}{l}\text { - Discriminar cores } \\
\text { - Melhorar a atenção }\end{array}$ & $\begin{array}{l}\text { - Melhorar equilíbrio } \\
\text { - Melhorar coordenação motora }\end{array}$ \\
\hline
\end{tabular}

\section{Entrevista pós-intervenção com as mães das crianças}

No decorrer da intervenção, foi observado o desenvolvimento cognitivo e motor das crianças e, ao final, foi realizada uma entrevista com as mães para ouvir suas opiniões sobre o desenvolvimento de seus filhos e sobre a própria intervenção.

Seis mães declararam-se satisfeitos com o desenvolvimento da nossa intervenção, relatando que seus filhos ficavam entusiasmados em participar das brincadeiras e que as crianças passaram a solicitar mais seus pais e irmãos para brincar.

Apenas uma mãe relatou que não notou diferença no comportamento de seu filho durante a realização da intervenção.

Entre os comportamentos desejados pelas mães para seus filhos em relação ao desenvolvimento cognitivo (aprender número e cores e melhorar a atenção) detectados na primeira entrevista com as mães, sete mães (100\%) relataram que houve o aprendizado de nomear cores. Cinco mães manifestaram entusiasmo com o aprendizado "rápido” de seus filhos. Uma mãe (14\%) relatou que sua filha tem se mostrado mais interessada, tendo mais atenção ao realizar algumas tarefas.

Quanto ao desenvolvimento motor, 6 mães (86\%) relataram que seus filhos adquiriram melhor coordenação e equilíbrio, caindo com menos freqüência. Para duas das mães (28,5\%), seus filhos estavam segurando melhor os objetos e uma delas disse que seu filho "até começou a pegar com as pontas dos dedos", indicando melhora nos movimentos de preensão e pinça. Segundo uma mãe (14\%), seu filho começou a se alimentar sozinho, o que a deixou muito satisfeita face ao seu desejo de que seu filho seja independente.

\section{Entrevista pós-intervenção com as professoras das crianças}

Com o mesmo propósito das entrevistas com as mães das crianças, foram feitas entrevistas com suas professoras. O objetivo era investigar alguma mudança significativa em relação ao comportamento da criança no ambiente escolar, seu desenvolvimento e suas participações em brincadeiras durante e após a intervenção.

A análise dos dados obtidos nas entrevistas pós-intervenção com as duas professoras mostram que ambas acharam o trabalho muito produtivo, relatando que seus alunos passaram a interagir com maior freqüência uns com os outros, solicitando mais vezes a atenção da professora em sala de aula.

Quanto a um aumento quantitativo em relação à atividade de brincar pelas crianças, relataram que isto não ocorreu, pois a rotina escolar, muitas vezes, não permite tal fato. No entanto, disseram que as crianças ficavam ansiosas para participarem de nossa pesquisa, perguntando diariamente quando a pesquisadora viria brincar.

As professoras relataram também que não era possível utilizar atividades lúdicas como recurso de ensino com maior freqüência em sala de aula, pois não "sobrava tempo", já que elas deveriam concluir o programa do calendário escolar.

Ficaram surpresas com o desenvolvimento das crianças durante as atividades lúdicas e que 
iriam incluir as atividades lúdicas como recurso de ensino no calendário do próximo ano letivo

As professoras relataram que todas as crianças melhoraram seu conhecimento sobre cores, duas crianças $(28,5 \%)$ aprenderam a diferenciar a textura "lisa" e uma criança (14\%) melhorou seu comportamento quanto à "atenção" em sala de aula.

Segundo as professoras, 71\% (5 crianças) melhoraram a coordenação e o equilíbrio, referindo que as crianças se mantinham sentadas sem perder o equilíbrio por mais tempo em sala de aula. Uma professora percebeu que um aluno (14\%) estava segurando o lápis e escrevendo melhor.

\section{CONCLUSÕES}

Mostrar que crianças com paralisia cerebral são capazes de aprender pode interferir quantitativa e qualitativamente em suas relações diárias, pois as mães e professoras podem começar a "olhar" para elas como crianças produtivas e melhorar a quantidade e a qualidade de suas interações. As mães puderam perceber que seus filhos eram capazes de aprender e algumas delas referiram um grande entusiasmo com o aprendizado "rápido" de seus filhos. Do mesmo modo, as professoras relataram que ficaram "surpresas" com o desenvolvimento das crianças durante o presente estudo.

Portanto, mães e professoras não possuíam conhecimento sobre as potencialidades dessas crianças. A dificuldade apresentada pela criança com paralisia cerebral espástica para movimentar-se dificulta suas manifestações e sua interação com o mundo e seu "corpo" pode esconder suas reais potencialidades. Assim, ela participa menos de atividades escolares e da família o que, possivelmente, faz com que mães e professoras interpretem negativamente o desenvolvimento dessas crianças e acabem, muitas vezes, diminuindo os estímulos necessários à sua evolução.

Indicando as potencialidades dessas crianças, estamos ajudando a desmistificar o "atributo profundamente depreciativo" imposto a elas, a que se refere Goffman ${ }^{21}$, sendo que tais crianças podem atuar produtivamente na sociedade.

Por meio das entrevistas realizadas com as mães após a intervenção, pudemos perceber que as crianças colaboradoras deste estudo começaram a procurar, com freqüência, seus familiares e colegas para brincar, aumentando a sua participação em atividades lúdicas e sociais.

De fato, no brincar estão importantes oportunidades à socialização das crianças. Um dos pontos cruciais que o educador enfrenta, ao lidar com crianças "diferentes", diz respeito ao isolamento imposto pela deficiência física. Não poder andar ou correr como as outras crianças, não conseguir participar de uma brincadeira com bola, representam uma enorme desvantagem em uma sociedade que espera que todos andem, falem, ouçam, vejam e se tornem independentes.

Ter amigos, brincar com eles, partilhar momentos agradáveis que o brincar pode oferecer, partilhar novos conhecimentos são aspectos essenciais para o desenvolvimento de uma criança.

É possível facilitar o desenvolvimento cognitivo e motor da criança com paralisia cerebral espástica por meio de atividades lúdicas; o difícil é transformar essas atividades em recursos de ensino que sejam utilizados, de fato, por seus professores. Embora tais atividades sejam consideradas importantes pelos educadores, e até por eles utilizadas, isso ainda ocorre quando há horários considerados vagos.

Os resultados deste estudo reforçam a necessidade de que as atividades lúdicas façam parte da prática escolar em sala de aula como recursos utilizados pelas professoras.

Cada criança é um ser único e, conseqüentemente, seu desenvolvimento é singular. Nesse sentido, singulares também devem ser os recursos e as atividades que proporcionam o seu desenvolvimento.

As crianças com paralisia cerebral espástica têm condições de participar, de brincar e de aprender. Nós é que necessitamos descobrir como Ihes proporcionar um ambiente favorável em que elas possam demonstrar do quanto são capazes.

Abstract: The current study aims at building a recreational environment of funs and games in
order lo stimulate cognitive and motor development of children suffering from spastic cerebral
palsy. Our theoretical foundation is Vygotsky's socio-historical theory, which considers that
recreational activities favor motor and cognitive development of children of pre-school age, by
enabling them to exploit their potentialities. As lhe motor difficulty exhibited by those children
usually prevents them from having a normal interaction with the environment they live in, these
potentialities may be hidden from society. Thus a recreational environment allowing the children
to interact with it proves efficacious for their development. Seven pre-school aged children
suffering from spastic cerebral palsy participated in a fun and games intervention program, which
amounted to 26 sessions. The results indicate that fun and games may favor motor and cognitive 
development of those children, since there was improvement with regard to their coordination, balance and grasping objects. An improvement in children's attention, particularly, related to learning and discriminating colors was also noticed. Our study results conclude the need for mere research to provide changes with regard to children's development teaching resources for professionals in this field. Those children are able to learn when their particularities are respected and their developing circumstances favored.

Key-words: Education. Special education. Cerebral palsy. Recreational activities. Development.

\section{REFERÊNCIAS}

1 Fonseca JP. Educar, assistir, recrear: um estudo de objetivos da pré-escola. São Paulo: Editora da USP; 1981. (Estudos e Documentos).

2 Aufauvre MR. Aprender a brincar, aprender a viver: jogos e brinquedos para a criança deficilente, opção pedagógica e terapêutica. São Paulo: Manole; 1987.

3 Kishimoto T. O jogo e a educação infantil. São Paulo: Pioneira; 1994.

4 Brougère G. Jogo e educação. Porto Alegre: Artes Médicas; 1998.

5 Carvalho LMG. As atividades lúdicas e a criança com paralisia cerebral: o jogo, o brinquedo e a brincadeira no cotidiano da criança e da família [dissertação]. Campinas (SP): Universidade Estadual de Campinas, 1998.

6 Elkonin DB. Psicologia do jogo. São Paulo: Martins Fontes; 1998.

7 Lorenzini MV. Brincando a brincadeira com a criança deficiente: novos rumos terapêuticos. São Paulo: Manole; 2002. Vygotsky LS. Dèfectologie et dèficience mentale. Paris: DelachauseetDiestlè; 1994.

9 Friedmann A. A evolução do brincar. In: Friedmann A. et al. O direito de brincar: a brinquedoteca. São Paulo: Scritta/ABRINQ; 1992.p.23-31.

10 Oliveira PS. Brinquedo e indústria cultural. Petrópolis: Vozes; 1986.

11 Silva e colaboradores. Memória e brincadeiras na cidade de São Paulo nas primeiras décadas do século XX. São Paulo: Cortez / CENPEC; 1989. (Biblioteca da Educação. Série 1. Escola, v. 7).
12 Brougère G. Brinquedo e cultura. São Paulo:Cortez; 1997.

13 Ide SM. O jogo e o fracasso escolar. In: Kishimoto TM. Jogo, brinquedo, brincadeira e a educação. São Paulo: Cortez; 1996. p.89-107.

14 Oliveira PS. Brinquedos artesanais e expressividade cultural. São Paulo: SescCelazer; 1982.

15 Le Boulch J. Educação psicomotora. Porto Alegre: Artes Médicas; 1988.

16 Meur A, Staes I. Psicomotricidade: educação e reeducação. São Paulo: Manole; 1984.

17 Finnie NA. O manuseio em casa da criança com paralisia cerebral. $2^{a}$ ed. São Paulo: Manole; 1980.

18 Ludke M, André MEDA. Pesquisa em educação: abordagens qualitativas. São Paulo: Pedagógica eUniversitária; 1986.

19 Willliams LCA, Aiello ALR. O Inventário Portage operacionalizado: intervenção com família. São Paulo: Memnon; 2001.

20 Blascovi-Assis MS. Lazer e deficiência mental: o papel da família e da escola em uma proposta de educação pelo e para o lazer [tese]. Campinas (SP): Faculdade de Educação Física da Universidade Estadual de Campinas; 1995.

21 Goffman E. Estigma: notas sobre a manipulação da identidade deteriorada. Rio de Janeiro: Zahar; 1988.

Recebido em 28/05/2004 Modificado em 11/08/2004 Aprovado em 02/09/2004 